\title{
ČETRTA GENERACIJA VOJSKOVANJA \\ 2. del: CELOVITA PRENOVA \\ NACIONALNOVARNOSTNEGA SISTEMA
}

\section{FOURTH GENERATION WARFARE \\ Part 2: COMPREHENSIVE REFORM OF THE NATIONAL SECURITY SYSTEM}

Povzetek V prispevku avtor nadaljuje obravnavo četrte generacije vojskovanja in se osredotoča na nujne spremembe v nacionalnovarnostnem sistemu. Najprej pa skuša osvetliti nekatere alternativne predloge ureditve nacionalnovarnostnega sistema, in sicer z vidikov, ki v Sloveniji niso pogosto izpostavljeni. Podrobneje opredeli glavne elemente četrte generacije vojskovanja, ki bistveno vplivajo na postavitev ustreznega nacionalnovarnostnega sistema. Avtor nima ambicije podrobneje opredeljevati vseh elementov tega sistema, želi pa izpostaviti tiste ključne spremembe, ki bi omogočale ustrezne odzive na četrto generacijo vojskovanja, Slovenski vojski pa, da se ustrezno odzove nanjo.

Ključne Nacionalnovarnostni sistem, četrta generacija vojskovanja, nevtralnost, besede demilitarizacija, Nato.

Abstract The article continues the discussion on the fourth generation warfare and focuses on the changes necessary in the national-security system. But first, it attempts to highlight some alternative views on how to restructure Slovenian national-security system through arguments that are not often presented to the public. To better understand why a new national-security system is needed, it analyses key elements of the fourth generation warfare. The article does not attempt to analyse in detail all the elements of a national-security system, but rather points to the key changes needed to set up a national-security system appropriate for the fourth generation warfare.

Key words National security system, fourth generation warfare, neutrality, demilitarisation, NATO. 
Uvod "Since it is absurd for the person to die for the interests of somebody or something else, the entire modern 'professional' model of armed forces fighting for their 'clients' is little better than prescription for defeat. I.../ However strong an army may be in other respects, where fighting-spirit is lacking everything else is just a waste of time. "1 (van Creveld, 1991, str. 191)

V četrti generaciji vojskovanja (angl. 4th generation warfare - 4GW), ki smo ji danes že priča, ni več jasne meje med vojno in mirom niti med vojaškimi in nevojaškimi sredstvi za vodenje vojn. Van Creveld v svojem delu celo izpostavlja paradigmo vojne kot nekaj, kar ima namen samo po sebi (van Creveld, 1991). Menimo, da danes lahko marsikje govorimo tudi o obrnjeni Clausewitzevi paradigmi, o politiki kot nadaljevanju vojne $\mathrm{z}$ drugimi sredstvi. ${ }^{2}$ Države, ki v teh okoliščinah čakajo na formalno razglasitev vojnega stanja ali izrednih razmer, da bi aktivirale vse zmogljivosti svojih nacionalnovarnostnih organov, so vnaprej obsojene na neuspeh. Kot ugotavlja Lind v svojem delu, je v središču četrte generacije vojskovanja kriza legitimnosti države. Povsod po svetu lahko opazimo, da državljani svojo primarno lojalnost vse manj vežejo na državo, vse bolj pa na različne druge entitete, bodisi na plemena, etnične skupine, religije, tolpe, ideologije bodisi na »projekte«. Mnogi se niso več pripravljeni boriti za državo, so se pa pripravljeni boriti za svojo novo primarno entiteto (Lind, 2015).

Martin van Creveld to vrsto vojskovanja imenuje »non-tinitian warfare«. S tem želi poudariti, da gre za vojskovanje, ki ne ustreza več Clausewitzevi trojici oblasti, vojske in ljudstva, v kateri so ti trije elementi ločeni, a povezani (Van Creveld, 1991). Gre za to, da oborožen boj ni več v izključni domeni vojske kot organizacije, vzpostavljene posebej za ta namen, nad katerim ima monopol država in v katerega ljudstvo (civilisti) ne posega. Cilj četrte generacije vojskovanja je uničenje moralnih vezi, ki omogočajo obstoj kohezivne celote. To je mogoče doseči z napadi, ki spodkopavajo ali ogrožajo temeljni preživitveni instinkt posameznika (napadi, pri katerih so cilj vsi in ni razlikovanja po pripadnosti, spolu, starosti, rasi itn.). To nato ustvarja nezaupanje in povečuje razpoke med skupinami (npr. nominalno levimi in desnimi v Sloveniji), ustvarja se negotovost, ki z zmanjševanjem zaupanja $\mathrm{v}$ prihodnost spodkopava gospodarsko aktivnost (Vandergriff, 2006).

V tem prispevku bomo natančneje opredelili četrto generacijo vojskovanja in njene elemente, da bi lahko nato pogledali, kakšen nacionalnovarnostni sistem bi morala država postaviti, da bi v tem novem svetu lahko zagotovila svojo legitimnost in se $\mathrm{s}$ sovražniki v njem uspešno spopadala. Nacionalnovarnostni sistem sodobne države obsega prvine varnostne politike, varnostnih struktur in varnostnega samoorganiziranja družbe (Grizold, 1999, str. 36). Seveda ne moremo, pa tudi nočemo, natančno obdelati vseh prvin tega, želimo le opozoriti na nujne spremembe

\footnotetext{
Ker je absurdno, da bi ljudje umirali za interese nekoga ali nečesa drugega, je celoten model modernih "profesionalnih « oboroženih sil, ki se bojujejo za svoje »kliente«, le nekoliko boljši kot recept za poraz ... Ne glede na to, kako močna je vojska v vseh drugih pogledih, če ji manjka bojnega duha, je vse drugo zapravljanje časa.

2 O takšni paradigmi bi lahko po našem mnenju govorili povsod, kjer ima v spopadih eno ključnih vlog islam.
} 
tako v varnostni politiki in strukturi sistema kot v dojemanju varnosti, ki jih je nujno dojeti in doumeti, če želimo biti uspešni v četrti generaciji vojskovanja.

Najprej bomo opozorili na nekatere pasti in zamolčana dejstva alternativnih predlogov reševanja problematike nacionalne varnosti, ki se pojavljajo v Republiki Sloveniji. Na prvi pogled se namreč zdijo nadvse privlačni in moderni, a dolgoročno pomenijo konec državnosti slovenskega naroda.

\section{MITI NEVTRALNOSTI, DEMILITARIZACIJE IN ČLANSTVA V NATU}

V Republiki Sloveniji imajo svoje zagovornike tudi zamisli o nevtralnosti, demilitarizaciji in izstopu iz Nata, ki so seveda povsem legitimne v demokratični družbi in so lahko medij za širšo razpravo o nacionalni varnosti. Težko pa se v luči zapisanih dejstev z njimi strinjamo. Kljub temu njihova sorazmerna popularnost kaže, da občutek ogroženosti velikega dela prebivalstva vendarle ni tako zelo velik. V tem delu bomo skušali opozoriti na nekatere pomanjkljivosti teh zamisli.

Slovenija ni otok, kot je Islandija ${ }^{3}$, in ne leži na skrajnem severu poloble, temveč na robu srednje Evrope in stičišču treh civilizacij. Evropske države brez oboroženih sil so Andora, Lihtenštajn in Vatikan ${ }^{4}$, druge države na svetu brez lastnih oboroženih sil so še otoške države v Pacifiku ali v Karibskem morju, z eno izjemo, to je Kostarika 5 . V Evropi je pet nevtralnih držav. Irska je dejansko otoška država, zato je njen položaj poseben. Da bi Republika Slovenija lahko razglasila nevtralnost, bi morala najprej dobiti mednarodne garancije, da se bo naša nevtralnost ob konfliktih tudi spoštovala. Avstriji je nevtralnost zagotovljena $\mathrm{z}$ državno pogodbo iz leta 1955, Finski pa z meddržavno pogodbo s Sovjetsko zvezo leta 1948. Tako pri Avstriji kot Finski gre za tako imenovano vsiljeno nevtralnost. Švici je bila nevtralnost najprej zajamčena z vestfalskim mirom leta 1648, nato je Francija leta 1789 zasedla velik del konfederacije. Z dunajskim kongresom leta 1815 je bilo podpisano poroštvo velikih sil, ki je Švici jamčilo trajno nevtralnost. Švedska v resnici nima mednarodne pogodbe, ki bi jamčila njeno nevtralnost, ampak nevtralnost utemeljuje na tradiciji. Kljub temu je treba vedeti, da jamstva sama po sebi ne zagotavljajo ničesar. ${ }^{6}$ Vse te države, z izjemo Irske, ki ima

\footnotetext{
Islandija je del majhne skupine držav, ki sicer formalno nimajo vojske, imajo pa druge elemente oboroženih sil. Sem spadajo še Haiti, Monako, Mauritius, Panama in Vanatu. Islandija je sicer članica Nata, nima pa svoje vojaške strukture. Njene obrambne sile predstavlja obalna straža, za notranjo varnost pa je zadolžena policija, ki ima v svoji sestavi tudi specialno enoto. Natu daje svoj finančni prispevek, s civilnimi strokovnjaki pa sodeluje tudi $v$ njegovih operacijah. Z ZDA ima sklenjen poseben obrambni sporazum.

${ }^{4}$ Vse tri so žepne države, med njimi pa ima predvsem Vatikan zelo veliko politično vlogo v svetu. Lihtenštajn je znan predvsem kot davčna oaza in svojo moč črpa iz ekonomije, Andora pa odgovornost za svojo varnost prenaša na Francijo.

5 Kostarika je brez oboroženih sil od konca državljanske vojne leta 1948. Njen geopolitični in geostrateški položaj je povsem drugačen od slovenskega, saj je tudi v geopolitični teoriji del otokov periferije. Sicer je Kostrika država z najvišjim indeksom sreče na svetu (Happy Planet Index).

${ }^{6}$ Kako trhle so lahko mednarodne garancije pa dokazuje primer Ukrajine. Ta se je ob razpadu Sovjetske zveze odpovedala svojemu delu jedrske oborožitve v zameno za jamstvo ozemeljske nedotakljivosti njenih meja, jamstvo so dale tako ZDA kot Rusija. Kako se dogovor spoštuje, ko gre za interese velikih sil, pa lahko vidimo ob dogajanju v Ukrajini.
} 
seveda zaradi otoške lege poseben strateški položaj, kljub svoji nevtralnosti vzdržujejo za slovenske razmere velike vojaške zmogljivosti in splošno vojaško obveznost. Res, da te štiri države namenjajo manj kot dva odstotka BDP za obrambne potrebe in da Avstrija in Švica v deležu BDP namenjata za obrambo celo manj kot Slovenija (vsaka po 0,8 odstotka). ${ }^{7}$ Toda vse te države imajo bistveno večji BDP, zato so primerljivejši podatki, koliko namenjajo za obrambo per capita (glej SIPRI-podatke o vojaških izdatkih za leto 2014). Izračuni pokažejo, da bi Slovenija za enako raven obrambnih izdatkov na prebivalca, kot jih namenjata Švica in Avstrija, morala svoj obrambni proračun povečati na 2,7 odstotka BDP (primerljivo s Švico) oziroma 1,6 odstotka (primerljivo z Avstrijo). Da bi bili primerljivi s Švedsko in Finsko, bi morali obrambni proračun dvigniti na 2,9 odstotka BDP. Glede na to, da je obrambni sitem v Republiki Sloveniji vse od nastopa gospodarske krize leta 2008 izrazito izgubljal in je struktura obrambnih stroškov zdaj povsem porušena, bi bili za vzpostavitev primerljivega stanja potrebni še precej večji vložki.

Republika Slovenija je članica Nata. V zavezništvih velja načelo solidarnosti in vzajemne pomoči. Kot je v svojem intervjuju dejal nekdanji direktor Direktorata za obrambno politiko MO Primož Šavc, se z zavezniki ne pogajamo, ampak posvetujemo. Proces Natovega načrtovanja je pregleden, do SV pa je Nato pokazal veliko razumevanja in jo ves čas gospodarske krize razbremenjeval. Vendar je SV vsakič zapravila izkazano zaupanje, saj svojega dela bremena ni uspela izpolniti ${ }^{8}$ (Pišlar, 2016). Prepogosto se poudarja le naš prispevek v zavezništvo, pozablja pa se, kaj vse Slovenija od zavezništva dobi, povsem pa se ignorirajo stroški, ki bi jih imeli brez članstva $v$ njem. S pomočjo zavezništva zagotavljamo nekaj zelo pomembnih zmogljivosti, za katere bi morali sicer kot resna država poskrbeti sami (Masten, 2016). Največkrat je v tem pogledu poudarjen nadzor zračnega prostora, saj bi razvijanje povsem lastnih zmogljivosti na tem področju zahtevalo vire, ki jih Slovenija tudi v najboljših časih pred gospodarsko krizo ni mogla financirati. A tu je še več drugih prednosti članstva, kot so: dostop do specialističnih usposabljanj, standardizacija, ki v marsičem poganja razvoj SV, dostop do vadišč in strelišč, ki jih v Sloveniji ni in jih ne bo, ter verodostojnost, ki ima tudi gospodarske posledice. ${ }^{9}$ Pozablja se še en pomemben vidik članstva v zavezništvu, in sicer jedrski dežnik. Kot dokazuje van Creveled v svoji knjigi, je verjetnost spopada (tako jedrskega kot konvencionalnega) med jedrskimi silami in njihovimi neposrednimi zaveznicami minimalna (van Creveld, 1991). To seveda ne preprečuje spopadov prek posrednikov in na ozemljih držav, ki niso v neposrednem zavezništvu z jedrskimi silami. Res pa se moramo zavedati, da so nekatere nejedrske članice zavezništva (predvsem majhne države) pred resnim vprašanjem. Članstvo v zavezništvu namreč še ne zagotavlja jedrskega odvračanja in kdo torej lahko zagotovi, da so velike članice v obrambi majhnih pripravljene uporabiti jedrsko orožje. Pomembno vprašanje je

Podatki veljajo za leto 2014, a primerjalno zdržijo tudi dolgoročno.

Nazadnje so leta 2013 druge zaveznice od SV prevzele kar šest ciljev, katerih težo v finančnem smislu Šavc ocenjuje na pol milijarde evrov (Pišlar, 2016, str. 11).

9 Seveda tudi souporaba vseh teh zavezniških zmogljivosti stane, vendar je to neprimerno manj, kot bi stalo, če ne bi bili članica zavezništva ali če bi morali te zmogljivosti razviti sami. 
tudi, ali bi bile majhne članice sploh pripravljene odobriti uporabo jedrskega orožja (četudi taktičnega) v obrambi svojega ozemlja in prebivalstva, saj njegova uporaba praktično pomeni uničenje države in prebivalstva. ${ }^{10}$ Menimo, da ne. Toda politiki oziroma ljudje na splošno smo občasno tudi neracionalna bitja.

Zaradi članstva v Natu se od nas sicer ne pričakuje, da bomo obrambne izdatke povečali na dva odstotka BDP. Pričakuje pa se, da bo naš prispevek k skupni varnosti vojaško relevanten. To niso nišne zmogljivosti tipa gorske šole in helikopterja za medicinsko evakuacijo, temveč dve bataljonski bojni skupini ${ }^{11}$. Ti dve zmogljivosti pomenita vojaško relevantni prispevek Slovenije v sistem kolektivne varnosti zavezništva. Tu je treba tudi ostro zavrniti vsakršne očitke o tem, da smo zaradi članstva v Natu prisiljeni kupovati oborožitev, s čimer naj bi domnevno služili interesom globalnega vojaškoindustrijskega kompleksa. Prvič, SV z obsegom svojih nakupov nikomur ne pomeni pomembnejšega kupca, ki bi za dalj časa lahko zapolnil katere koli proizvodne zmogljivosti, z vidika vojaškoindustrijskega kompleksa so naše potrebe precej butične narave. Drugič, ne velja niti očitek, da kupujemo samo »ameriško orožje«. SV je že po vstopu v Nato pridobila rusko ladjo (Triglav) in s sistemi ruske proizvodnje (Igla) opremila svojo zračno obrambo. Imamo švicarske PC-9, avstrijske šestkolesnike, finske osemkolesnike ${ }^{12}$, francoske in kanadske helikopterje, belgijsko osebno oborožitev, italijanske pištole, izraelske protioklepne sisteme itn. V resnici je ameriških zgolj nekaj vozil 4 x 4 tipa Hummer in MRAP, ki pomenijo povsem nepomemben del bojne moči SV.

\section{ELEMENTI ČETRTE GENERACIJE VOJSKOVANJA}

V prvem članku in uvodu smo že opredelili, kaj četrta generacija vojskovanja je. Da bi bolje razumeli, kakšen nacionalnovarnostni sistem potrebujemo, moramo nekoliko podrobneje opredeliti ključne elemente tega vojskovanja.

Klasična vojaška teorija pozna tri ravni vojskovanja - strateško, operativno in taktično. Tem trem se v četrti generaciji pridružijo še moralna, mentalna in fizična raven bojevanja ${ }^{13}$. Pri tem je najmanj pomembna fizična raven, najbolj pa moralna. Hkrati nove tri ravni vojskovanja ne pomenijo, da klasičnih ni več ali da so v četrti generaciji nepotrebne. Nasprotno, v njej se fizična, mentalna in moralna raven pojavljajo na vseh treh klasičnih ravneh bojevanja.

\footnotetext{
${ }^{10}$ To opcijo je preigravala tudi študija RAND, ki se je ukvarjala z vprašanjem morebitne ruske agresije na baltske članice zavezništva (Shlapak, 2016)

"Nova klasifikacija Natovih zmogljivosti (2016) ne govori več o motorizirani in mehanizirani pehoti, ampak ponovno uvaja staro ločevanje na lahko, srednjo in težko pehoto. V SV bomo tako ponovno govorili o lahki, srednji in težki bataljonski bojni skupini.

${ }^{12}$ Od 135 predvidenih jih imamo le 30. S tem smo tudi zavestno odstopili od zavez do zaveznikov, saj je bilo 135 vozil predvidenih za oblikovanje dveh mehaniziranih bojnih skupin, 30 pa jih ne zadostuje niti za eno in tako zdaj govorimo le o srednji bataljonski bojni skupini, a glede na novo klasifikacijo zavezništva ta ne ustrezajo niti srednji bataljonski bojni skupini.

${ }_{13}$ Te je prvi identificiral ameriški letalski polkovnik in vojaški teoretik Jonh Boyd, podrobneje pa o njih pišeta tudi Lind in Thiele v svojem delu »4th Generation warfare handbook«.
} 
Elementi četrte generacije vojskovanja, ki se neposredno prenašajo iz predhodne tretje $^{14}$, so usmerjenost navzven, decentraliziranost in natančnost. Povsem novi elementi vojskovanja, ki jih najdemo v četrti generaciji, so dominantnost moralne ravni, moč šibkosti, deeskalacija, proporcionalnost, sposobnost empatije in razumevanje kulture (Lind \& Thiele, 2015). Posamezne elemente je treba podrobneje predstaviti:

- usmerjenost navzven: gre za osredotočenost na situacijo, rezultat in delovanje, ki ga zahteva situacija, ne pa na vnaprej določena pravila delovanja, procese in metode. Standardizirane taktike in predvidljivi vzorci so nezaželeni, poveljnike je treba soditi glede na rezultate in ne glede na to, ali so vse opravili skladno z zapisanimi pravili15;

- decentralizacija: tok in distribucija informacij morata biti decentralizirana vse do najnižjih poveljniških ravni, celo do ravni posameznika. To seveda hkrati zahteva veliko medsebojnega zaupanja v celotni liniji PINK;

- natančnost: ta element se nanaša na zanko OODA (angl. Observe-OrientDecide-Act) ${ }^{16}$, v kateri je pomembno, da celoten proces izvedete hitreje, kot vaš sovražnik, vendar je natančnost korakov opazovanja in orientacije pomembnejša od hitrosti. Drugi akterji v četrti generaciji vojskovanja imajo običajno zelo ploske organizacijske strukture, zato jim to ne predstavlja prevelikih težav. Nacionalnovarnostni sistemi držav morajo svojo organizacijsko strukturo narediti precej bolj plosko, če v tem procesu želijo ostati kompetitivni;

- dominantnost moralne ravni: $\mathrm{v}$ četrti generaciji vojskovanja moralna raven prevladuje nad vsemi drugimi. Če vojske izgubljajo na moralni ravni, potem uspehi na kateri koli drugi ravni vojskovanja ne bodo prinesli zmage (prim. ZDA v Vietnamu);

- moč šibkosti: ta element je neposredno povezan z dominantnostjo moralne ravni, zaradi katere imajo šibki v četrti generaciji vojskovanja običajno več moralne moči od močnih. Eden prvih, ki je izkoristil ta element, je bil Manhatma Gandhi s svojim vztrajanjem na nenasilnem odporu. Nihče namreč ne mara krepkih fantov, ki izkoriščajo svojo fizično premoč za zmago oziroma za ustrahovanje fizično šibkejših, enako velja za vojske v četrti generaciji;

- deeskalacija: je prav tako povezana z dominantnostjo moralne ravni in močjo šibkosti. Večina sodobnih družb ima raje manj in ne več nasilja. Zato je danes za zmago treba najti načine za ustrezno deeskalacijo nasilja. V tem pogledu so primernejše od vojaških policijske taktike in tehnike. Seveda to ne pomeni, da v četrti generaciji vojskovanja ni situacij, v katerih bi bilo nujno stopnjevanje nasilja. Večinoma na taktični in mentalni ravni te situacije seveda so, vendar je treba doseči, da je uporaba superiorne fizične moči pravilno odmerjena in čim krajša;

- proporcionalnost: je prav tako povezana s potrebo po tem, da oborožene sile niso razumljene kot nasilnež, ki mu ni mar za prebivalstvo. Uporaba tankov, letal in

\footnotetext{
14 Tudi o teh smo podrobneje pisali v prvem članku.

${ }_{15}$ Jasno, da tu ne gre za pravila, ki uravnavajo vojskovanje v pravnem smislu, njihovo kršenje bi pomenilo vojni zločin. Gre za pravila, ki uravnavajo delovanje posameznikov, enot in vojsk na taktični, operativni in strateški ravni.

${ }^{16}$ Avtor tega procesa je ameriški polkovnik in vojaški teoretik John Boyd.
} 
artilerije je seveda nujna $\mathrm{v}$ posebnih situacijah, ko je na primer tudi sovražnik opremljen z njimi ali pa je razmerje sil v neposrednem spopadu izrazito na strani sovražnika. Nikakor pa ni priporočljiva njihova uporaba proti lahko oboroženim skupinicam gverilcev. V tem primeru namreč obstaja veliko tveganje, da bo uničena tudi infrastruktura miroljubnega dela prebivalstva in bodo nepotrebne civilne žrtve, hkrati pa na moralni ravni vojne deluje izrazito kontraproduktivno in povečuje simpatije do državnih sovražnikov;

- sposobnost empatije: deeskalacija in proporcionalnost zahtevata sposobnost empatije. Te ni mogoče ukazati, temveč jo je treba razviti med usposabljanjem. V tem pogledu je nujna integracija pripadnikov oboroženih sil v okolje, v katerem delujejo. Na prvi pogled se to zdi tudi v nasprotju z željo po zaščiti lastnih sil, v resnici pa jo integracija z lokalnim prebivalstvom povečuje. Če namreč pomislimo logično, je veliko težje streljati na nekoga, ki ga poznaš in srečuješ, kot pa na popolnega neznanca. To velja za primere, ko (večinoma poklicne ${ }^{17}$ ) oborožene sile delujejo doma, kot tudi za delovanje na tujem;

- razumevanje kulture: empatija in integracija omogočata učinkovito razumevanje kulture, to je razumevanje tega, kako družba deluje ${ }^{18}$. V četrti generaciji vojskovanja večina uporabnih obveščevalnih podatkov prihaja od človeških virov (HUMINT) - torej civilnega prebivalstva in vojakov samih. Kot je to značilno za manevrsko vojskovanje tudi v četrti generaciji vojskovanja, taktično raven delovanja poganjajo izvidniške in ne obveščevalne informacije. To preprosto pomeni, da bodo informacije za delovanje taktičnih enot večinoma prihajale od spodaj in ne od zgoraj, iz štabov, zaradi česar je splošna sposobnost dojemanja kulture okolja, v katerem delujemo, izjemno pomembna.

Vojske nacionalnih držav bodo zaradi svoje tehnične premoči in državne organiziranosti na moralni in strateški ravni skoraj vedno v podrejenem položaju, tudi na domačem ozemlju. Ljudje izgubljajo zaupanje $v$ državne institucije ${ }^{19}$ in se vse bolj identificirajo z drugimi nedržavnimi skupinami ali gibanji, čeprav uživajo svoboščine in pravice, ki jih zagotavlja prav ta država. Pravice in svoboščine se dojemajo kot samoumevne in posamezniki države ne vidijo več kot njihovega poroka - za to je odgovorna tudi država z depersonalizirano birokracijo in odsotno politiko. To velja tudi za Slovenijo. Tehnična premoč sama po sebi zagotavlja simpatije izrazito tehnološko šibkejši strani (sindrom Davida in Goljata).

\footnotetext{
${ }_{17}$ Menimo namreč, da je vprašanje empatije in integracije nekoliko manjše v primeru naborniških oboroženih sil, ko te delujejo na svojem ozemlju.

18 To je spet precej pomembneje pri delovanju na tujem, ni pa nepomembno niti, ko oborožene sile na takšni ali drugačni nalogi delujejo tudi na domačem ozemlju. Sploh poklicni pripadniki oboroženih sil vse bolj ugotavljajo, da jih družba, v kateri živijo in za katero delajo, čedalje manj razume - seveda velja tudi obratno.

${ }^{19}$ Kako malo zaupanja $v$ državne institucije imajo Slovenci, pa tudi nekateri drugi narodi v Evropi, je na primer pokazalo poročilo iz raziskave Evropska unija: širitev, demokracija, zaupanje v institucije; Mnenjska klima v Avstriji, na Madžarskem, v Sloveniji in v jugovzhodni Evropi, v kateri je s slovenske strani sodelovala Fakulteta za družbene vede, IDV, CJMMK, Ljubljana (dostopno na http://www.cjm.si/sites/cjm.si/files/File/aktualne raziskave/porocilo-EU-Balkan.pdf, str. 10). Poročilo je iz leta 2006, raziskava OECD pa je pokazala, da je zaupanje v državne institucije v Sloveniji med letoma 2007 in 2014 vztrajno padalo.
} 
V četrti generaciji vojskovanja si morajo oborožene sile zastaviti stvarne strateške cilje (Lind \& Thiele, 2015). Vojska sama, doma ali v tujini, ne more graditi zaupanja $\mathrm{v}$ državne institucije, $\mathrm{v}$ vladavino prava in legitimnost države. To ni nikoli bila njena vloga oziroma naloga $\mathrm{v}$ obrambi nacionalnega ozemlja in prav tako ne more biti pri delovanju v tujini.

\section{NACIONALNOVARNOSTNI SISTEM ZA SOOČANJE S ČETRTO GENERACIJO VOJSKOVANJA}

\subsection{Razmišljanja v RS}

Igor Kotnik in Iztok Podbregar v svojih razmišljanjih in predlogih o nadaljnjem razvoju Slovenske vojske zastopata dve nasprotujoči si stališči o obsegu in s tem povezanim značajem SV. Podbregar v svojem prispevku v SVI 2011 in intervjuju za revijo Mladina govori o popolnem reinženiringu nacionalnovarnostnega sistema in znotraj tega o stečaju SV, policije in nekaterih drugih subjektov nacionalnovarnostnega sistema. Pri tem sicer ne govori o potrebnem obsegu vojske, saj bi jo po njegovem predlogu popolnoma nadomestili z novo paravojaško organizacijo, ki bi opravljala tako naloge policije kot vojske. ${ }^{20}$ Govori samo o skupnem obsegu obrambnih sil, ki bi ga lahko zmanjšali za polovico ali vsaj tretjino - z zdajšnjih 21.000 na skupaj 12.000 pripadnikov ${ }^{21}$ (Podbregar, 2011). Če pustimo ob strani razpravo o tem, kako nevarno je tako razmišljanje za demokratično družbo, pa ne moremo mimo tega, kaj bi ta predlog pomenil za obseg SV. Predlog je usmerjen v zmanjšanje komponente, namenjene oboroženemu boju, na približno 4500 pripadnikov, s katerimi bi pokrili le vojaške zaveze do $\mathrm{Nata}^{22}$. Kotnik na drugi strani z vidika migrantske krize in spremenjenih razmer v svetu predlaga SV, sestavljeno iz pripadnikov stalne sestave, in ponovni razmislek o teritorialni obrambi in narodni zaščiti, pri čemer pa opozarja, da je sedanji koncept strateške rezerve neuresničljiv v zastavljenih časovnih in organizacijskih okvirih (Kotnik, 2015). Končni obseg takšne strukture, namenjene oboroženemu boju, lahko ocenimo na približno 35.000 pripadnikov.

S predlogoma se lahko strinjamo ali ne, zato v strokovni in laični javnosti najdemo goreče pristaše in nasprotnike obeh predlogov. Res pa je, da temeljita na popolnoma različnih premisah organiziranosti nacionalnovarnostnega sistema in spopadanju z grožnjami v sodobnem varnostnem okolju, o katerem smo več razpravljali $\mathrm{v}$ prejšnjem članku.

\footnotetext{
${ }^{20}$ Vojska in policija kot ločena podsistema naj torej sploh ne bi obstajali.

${ }^{2 I}$ Pri tem je v intervjuju v Mladini nekoliko nerodno uporabljen termin obrambne sile, saj so obrambne sile, kot izhaja iz Ustave RS, na podlagi ZoObr (3. člen) sestavljene iz vojske, ne pa tudi policije in drugih subjektov nacionalnovarnostnega sistema, kot bi to bilo razumljeno iz zapisanega v Mladini.

${ }_{22}$ Skladno s Podbregarjevim predlogom to pomeni obseg pripadnikov, ki je potreben za uresničitev vseh sprejetih Natovih ciljev zmogljivosti za RS. Primeren in potreben element PINK, VIU in admin-logististike bi bil skladno s predlogom generala Podbregarja del novega super ministrstva za varnost.
} 


\subsection{Parametri poenotenja razmišljanja o nacionalnovarnostnem sistemu}

Grizold ločuje obrambno, zaščitno-reševalno in notranjevarnostno prvino znotraj varnostnih struktur nacionalnovarnostnega sistema sodobne družbe. Pri tem ima vsaka prvina posebne naloge, v splošnem pa so naloge obrambe zagotavljanje varnosti pred zunanjim sovražnikom, ohranjanje notranje varnosti ter zakonitosti in reda, zaščita infrastrukture in zaščitno-reševalno delovanje ob naravnih in drugih nesrečah, pri čemer posamezne prvine načeloma naj ne bi posegale $\mathrm{v}$ delovno področje druge (Grizold, 1999).

Prepričani smo, da v četrti generaciji vojskovanja ne moremo več ločevati obrambnih in notranjevarnostnih prvin sistema kot strogo ločenih elementov zunanje in notranje varnosti Republike Slovenije. Sovražniki in orodja v tej generaciji vojskovanja ne poznajo meja ali jih ne priznavajo, največkrat državi odrekajo vsakršno legitimnost, ločevanje struktur zunanje in notranje varnosti ter s tem povezano neusklajenost in počasnost odzivov pa bodo znali še kako izkoristiti. Zato se moramo začeti pogovarjati o nacionalnovarnostnem sistemu in celovitosti njegove ureditve. V strokovni in laični javnosti se s stališča nacionalnovarnostnega sistema pogosto razpravlja o povsem nepomembnih stvareh. Taki in drugačni strokovnjaki so, vede ali nevede, usmerjeni na raven razprav, na primer o količini uporabnih neprebojnih jopičev, ki se obravnavajo kot bi bile eden bistvenih elementov nacionalnovarnostnega sistema. ${ }^{23}$ Razpravlja se o doseganju zmogljivosti, za katere smo se zavezali zaveznikom, o tako imenovani narodni gardi itn. V resnici pa bi se na strateški ravni najprej morali opredeliti do bistvenih parametrov, nujnih za uspešno delovanje nacionalnovarnostnega sistema. Ti so povezani z doktrino, šolskim sistemom in organizacijo celotnega sistema. Iz teh razprav bi sledili sklepi o vrstah, obsegu in organizaciji posameznih elementov, mobilizaciji ${ }^{24}$, bojni pripravljenosti in o birokraciji v nacionalnovarnostnem sistemu.

Razprava o sodobnem varnostnem okolju in našem mestu ter vlogi v njem bi nam morala dati odgovor na vprašanje, kakšna bo za nas naslednja vojna. Nato nam je na to že ponudil odgovor, zanj naslednja vojna pomeni hibridni spopad visoke intenzivnosti (Nato, 2015, str. 5 in 6). Razpravljamo lahko le še o tem, kaj lahko pričakujemo na ozemlju RS znotraj tega spopada - zgolj protiterorizem ali morda hibridni konflikt nizke intenzivnosti, kakršne lahko opazujemo na Natovem južnem krilu (od Afganistana do Libije). Odgovor na to vprašanje je v prejšnjem prispevku. Pri tem je predpostavka, da bo naslednja vojna enaka osamosvojitveni vojni leta 1991, povsem napačna in pomeni škodljivo dogmo za ves nacionalnovarnostni

\footnotetext{
${ }^{23}$ Tak je bil denimo prispevek medijske hiše POP TV, v katerem je sodeloval obramboslovec dr. Klemen Grošelj na http://www.24ur.com/novice/slovenija/komentar-gre-za-odnos-in-ponos.html. To seveda ne pomeni, da vprašanje zaščite pripadnikov SV ni pomembno, toda prej bi se morali pogovarjati o bistveno pomembnejših stavreh, kot npr. o tem, v kakšni vojni oz. oboroženem spopadu bodo naši vojaki te jopiče sploh uporabljali.

${ }^{24}$ Mobilizacijo razumemo $v$ smislu postopkov in aktivnosti, s katerimi preidemo iz stanja miru v vojno ali krizno stanje. 25.člen veljavnega Zakona o obrambi jo opredeljuje kot: »/.../ obsega postopke in aktivnosti, s katerimi Slovenska vojska in državni organi (torej tudi Policija? o.p.) v skladu z načrti preidejo na delovanje v vojnem stanju, ostali izvajalci civilne obrambe in civilna zaščita pa v stanje pripravljenosti za izvajanje nalog v vojni.«
} 
sistem RS. ${ }^{25}$ Geopolitične okoliščine so namreč povsem spremenjene. Iz odgovorov na temeljne parametre varnostnega okolja RS bi sledili tudi odgovori na vprašanja doktrine, vrste, obsega in organizacije nacionalnovarnostnega sistema.

Nujna je razprava o strukturi nacionalnovarnostnega sistema in SV znotraj njega, ki bo dovolj ploska, da bo omogočala kompetitivnost v zanki OODA med spopadanjem s sovražniki v četrti generaciji vojskovanja. ${ }^{26}$ Odločiti se moramo, kakšna naj bodo razmerja med stalno sestavo, prostovoljno pogodbeno rezervo in vojaško strateško rezervo $^{27}$ in zakaj naj bodo takšna. Treba bi bilo razmišljati o večji usklajenosti nacionalnovarnostnih institucij po ruskem vzoru. V Ruski federaciji je na področju nacionalne varnosti izjemen poudarek na usklajevanju prizadevanj vseh vladnih institucij in oboroženih sil, pri čemer sta bili pristojnost in odgovornost za njihovo usklajevanje zaupani generalštabu oboroženih sil. Ta je $\mathrm{v}$ ta namen ustanovil Nacionalni center za obrambo Ruske federacije, ki je pristojen in odgovoren za usklajevanje več kot 50 institucij, vključenih v sistem njene nacionalne varnosti (Johnson, 2015, str. 4 in 5). Rusija je tako po letu 2009 izvedla obsežne vojaške reforme in reorganizirala svoj obrambno-varnostni sistem, in sicer tako, da je sposobna $\mathrm{v}$ štirih dneh po sprejetju odločitve izvesti operacijo, kot je na primer priključitev Krima. Tega Nato nikakor ni sposoben, niti ni tega sposobna katera koli druga posamična zahodna sila. To seveda ne pomeni, da so Rusi v štirih dneh prišli s praznega lista papirja do zasedbe Krima. Načrti so bili seveda pripravljeni vnaprej skladno z jasno geopolitično usmeritvijo ${ }^{28}$ (predavanje Žabkar, 2016, GS̆SV). Oborožene sile Ruske federacije so brez dvoma razvile tudi nekaj zelo sodobnih zmogljivosti, predvsem za specialne sile (Bukkvoll, 2015). Vendar ne gre za to, da bi preprosto prevzeli neke tuje (v tem primeru ruske) rešitve, temveč da se uveljavijo podobna načela, ki bi omogočila bolj ploski sistem vodenja in poveljevanja ter en organ, ki usklajuje odločitve, skladne s političnimi direktivami, in jih hitro prenaša na vse udeležence v nacionalnovarnostnem sistemu.

\subsection{Normativna ureditev sistema}

Ustava RS (124. člen) določa, da vrsto, obseg in organizacijo obrambe nedotakljivosti in celovitosti državnega ozemlja ureja zakon (Državni zbor, 2013). Vse, kar ne spada $\mathrm{v}$ to ustavnopravno kategorijo, bi morali urejati z drugimi zakoni (zakon o SV, zakon o Policiji itn.). Nov oziroma prenovljen zakon o obrambi bi moral ponuditi rešitve, skladne $\mathrm{z}$ rezultati omenjenih razprav. Menimo, da so sedanje rešitve v zakonu o obrambi večinoma neprimerne za izzive četrte generacije vojskovanja. V izhodišču

\footnotetext{
${ }_{25}$ To pa še ne pomeni, da osamosvojitvena vojna ni bila dobro vodena ali da so organizacijske rešitve neuporabne. Toda nekritično prenašanje rešitev iz leta 1991 bi bilo napačno.

${ }^{26}$ To izhaja tudi iz priporočil za zavezništvo in posamezne članice, ki jih najdemo v Framework for Future Aliance Operationn (NATO, 2015).

${ }^{27}$ Znotraj tega pa predvsem o tem, ali vse tri elemente sploh potrebujemo, in če jih, moramo imeti jasne odgovore, zakaj in čemu služijo znotraj doktrine, ter jasno zavedanje, koliko nas vzdrževanje posamezne strukture stane.

${ }^{28}$ Kljub temu pa bi bilo napačno domnevati, da je Ruska federacija sposobna konvencionalnega vojskovanja, ki bi šlo prek njene bližnje soseščine ali celo konvencionalnega spopada z Natom. To ni realno v luči njenih mnogih notranjih težav, ki zahtevajo osredotočeno pozornost in ustrezno alokacijo sredstev (Renz, 2014, str. 79).
} 
sedanjega zakona je bilo, da se poleg navedenega v 124. členu Ustave RS »pri urejanju vojaške organizacije čim bolj upoštevajo splošni predpisi« (MO, 2016, str. 1). Temeljni zakon je bil sprejet leta 1994, nato pa večkrat spremenjen ali dopolnjen, skladno s potrebami obrambnega sistema, nazadnje leta 2015. Menimo, da je temeljno izhodišče, po katerem se pri urejanju vojaške organizacije čim bolj upoštevajo splošni predpisi, sicer dobronamerno, a žal prevečkrat škodljivo uporabljeno. Zakon, ki ureja vrsto, obseg in organizacijo obrambne nedotakljivosti in celovitosti državnega ozemlja, mora predvsem v celoti prepoznati posebnosti krizne situacije, izrednih razmer in vojne ter zahteve, ki jih te prinašajo v mirnodobne priprave nanje. Čeprav gredo nekatere predlagane spremembe zakona o obrambi po našem mnenju v pravo smer (MO, 2016, str. 7-12), imajo nekaj hudih pomanjkljivosti in ne izpolnjujejo zahtev delovanja v četrti generaciji vojskovanja. Zakon namreč ne ponuja nove ploske ureditve nacionalnovarnostnega sistema in ne prinaša nikakršnega bistvenega napredka pri usklajevanju sedanjih elementov nacionalnovarnostnega sistema. Omogoča sicer nekatere rešitve, ki so v zavezništvu že dalj časa poznane (npr. krizno upravljanje in oblikovanje obrambnega štaba), vendar ne daje nikakršnih poroštev, da se bodo te rešitve tudi uveljavile. Predvsem pa te rešitve po našem mnenju ne bodo zadostovale zahtevam po hitrosti odločanja v zanki konfliktov (OODA) četrte generacije vojskovanja. Hkrati predlog izpušča omembo vojaškoteritorialnih in operativnih poveljstev ${ }^{29}$. V četrti generaciji vojskovanja sta ravno prostorska razpršenost in teritorialna prisotnost ključnega pomena za uspeh. Tehnika je seveda pomembna, a v nobenem primeru ne more nadomestiti prisotnosti moštva na terenu za zagotavljanje legitimnosti države.

Med pomanjkljivostmi se v obrambne strukture s tem zakonom vnaša nekaj povsem neprimernih rešitev, ki veljajo za druge javne uslužbence in delavce na splošno. Vsekakor se strinjamo s tem, da »poklicni pripadniki stalne sestave vojske zaradi opravljanja vojaške ali druge službe na obrambnem področju ne smejo biti v slabšem položaju, kot so drugi javni uslužbenci« in da »je treba upoštevati tako specifičnosti vojaške službe kot tudi mednarodnopravna izhodišča na področju delavskih pravic« (MO, 2016, str. 8). Toda za uspešno delovanje nacionalnovarnostnega sistema $\mathrm{v}$ četrti generaciji vojskovanja je poleg ustreznih vrst obrambne organiziranosti, obsega (SatS, PPRS, VRS) in organizacije (ploskost strukture VIP in PINK) ključno V celoti prepoznati specifičnost vojne ali krizne situacije oziroma oboroženega spopada in zahteve, ki jih ta prinaša $\mathrm{v}$ mirnodobne priprave nanjo. Te izhajajo iz zahteve o stalni pripravljenosti (24 ur, sedem dni v tednu) in skrajnih psihičnih in fizičnih obremenitvah, ki jih dolgotrajnejši oborožen spopad prinaša ${ }^{30}$, in se bistveno

\footnotetext{
${ }^{29}$ V obrazložitvi predloga zakona je zapisano, da se pojma vojaškoteritorialno in operativno poveljstvo umikata iz zakona, ker teh poveljstev v SV ni več. A že leta 2017 naj bi se ponovno vzpostavilo operativno poveljstvo. Izkušnje pa kažejo, da je SV dovoljeno samo tisto, kar je izrecno zapisano. Kako bo potem minister ali kdor koli drug lahko oblikoval vojaškoteritorialna in/ali operativna poveljstva, če se za to izkažejo potrebe, je po avtorjevem mnenju zelo vprašljivo, čeprav tega ministru nič ne preprečuje.

${ }^{30}$ Gre za bistvene razlike od vseh preostalih poklicev, ki pokrivajo področje varnosti in so prav tako del javne uprave (na primer policisti, pazniki v zaporih, gasilci) ali pa del zasebnega sektorja (varnostniki, redarji ipd.). Vsi ti prav tako kot vojaki izpostavljajo svoja življenja in se med svojim delom znajdejo v situacijah, ki so fizično in psihično izjemno zahtevne, toda te obremenitve nikjer niso tako dolge in intenzivne, kot so pri vojakih. Res pa v miru vojaki teh obremenitev ne čutijo, zato je še toliko pomembneje, da imajo v mirnodobnem okolju usposabljanja možnost za čim bolj realne simulacije.
} 
razlikujejo od vseh drugih poklicev v javni upravi. Vojak ${ }^{31}$ pač ne moreš biti osem ali 12 ur na dan oziroma v izmenah po osem ur, nato pa si preostanek dneva ali tedna samo in zgolj civilist. Vojna pač ni situacija, ki bi vojaški osebi to dopuščala, vojaške osebe so predvsem zato, da so pripravljene na stanje vojne in ne miru, pri čemer je uveljavljanje enakih pravil in pogojev, kot veljajo za druge javne uslužbence, v marsikaterem pogledu škodljivo in kontraproduktivno ${ }^{32}$. Zakon mora zato prepoznati tiste pravice delavca oziroma javnega uslužbenca, ki vojaku onemogočajo ustrezno pripravo na vojno in tako posredno ogrožajo njegovo življenje. V zameno mora vojaškim osebam, ki jim je neka pravica omejena, ponuditi ustrezno družbeno in ustavno sprejemljivo izravnavo- finančno ali kakšno drugačno. ${ }^{33}$

\subsection{Spremembe v organizacijski kulturi celotnega sistema}

Za delovanje $\mathrm{v}$ četrti generaciji vojskovanja potrebujemo tudi zakon in iz njega izhajajočo normativno ureditev, ki bo podlaga za spremembo kulture $\mathrm{v}$ nacionalnovarnostnih institucijah. Organizacijska kultura je sestavljena iz artefaktov, vrednot ter prepričanj in temeljnih predpostavk. M. Jakič v svoji monografiji, ki je nastala iz doktorske disertacije, ugotavlja, kakšni so bili posamezni elementi organizacijske kulture SV kmalu po prehodu iz naborniškega v poklicni sistem popolnjevanja. Iz nje izhaja, da je organizacijska kultura SV povsem neprimerna za četrto generacijo vojskovanja, saj so njeni bistveni elementi (pobuda, samodisciplina, decentralizacija in fleksibilnost) v SV zelo slabo ovrednoteni ${ }^{34}$ (Jakič, 2010). Seveda SV ni edini element nacionalnovarnostnega sistema in organizacijska kultura SV ni nujno tudi organizacijska kultura drugih udeležencev v sistemu, je pa SV ključni nosilec sistema $\mathrm{v}$ četrti generaciji vojskovanja in kot taka nosilec organizacijske kulture. Napačno bi bilo predpostavljati, da se sprememba organizacijske kulture lahko zgodi čez noč in zgolj s spremembo normativnih dokumentov. Ti lahko dajo

\footnotetext{
${ }^{31}$ Izraz vojak v tem delu uporabljamo tako za kategorijo vojakov kot tudi podčastnikov in častnikov.

${ }^{32}$ Ni pa vedno tako. Treba je pač prepoznati, v katerem delu je vojaška profesija specifična in v katerem ne.

${ }^{33}$ Menimo, da je npr. pravica delavca do neprekinjenega dnevnega in tedenskega počitka oz. dovoljena tedenska obremenitev tak primer, pri katerem bi bilo pravico do počitka treba prilagoditi specifičnosti vojaške organizacije. Vojna se ne prekine po 12 urah niti ne po šestih dneh. Traja, dokler traja. In v tem smislu mora tudi zakon o obrambi omogočiti ustrezne priprave oz. usposabljanje za vojno. Zakon bi moral nekomu (običajno vodji) naložiti, da med usposabljanjem zagotovi počitek (v uniformi, opremi in taktični situaciji), ki omogoča smiselno usposabljanje. S tem bi omogočil ustrezne priprave na vojno in hkrati tudi zahteval od poveljujočega, da ustrezno poskrbi za svoje podrejene, tako v miru kot v vojni, skladno z načelom, da se usposabljamo tako, kot se bomo bojevali.
}

Druga taka pomanjkljivost predloga novega zakona o obrambi je usklajevanje z ZPIZ-2 in večanje starostne omejitve za vojake. $4 \mathrm{GW}$ je tako psihično kot fizično izjemno zahtevno okolje in pričakovanje, da bodo 60-letniki in starejši v njej ustrezno delovali, je iluzija - mirnodobno okolje pač ni vojna. Že sedanje rešitve s starostno omejitvijo 45 let in poklicnim upokojevanjem povzročajo, da je SV med najstarejšimi v Natu. Povečanje teh dveh omejitev bo stanje samo še poslabšalo in SV bo v resnici postala vojska starcev. Zakon bi moral tu ponuditi rešitve, ki bi ustrezno finančno ali drugače nadomestile depriviligiran položaj vojaških oseb v primerjavi s preostalim javnim sektorjem.

${ }^{34}$ Z nadrejenimi je bilo nezadovoljnih kar $51 \%$ anketiranih (str. 174). Med osebnostmi značilnostmi vodje sta samoiniciativnost (ena osnovnih značilnosti vodje v $4 G W$ ) in discipliniranost ocenjeni zelo slabo. Tudi inteligentnost in splošna razgledanost kotirata razmeroma nizko (str. 176). Vrednote organizacije so sicer blizu vrednotam pripadnikov SV (str. 203) in tudi pravila se bolj ali manj spoštujejo (str. 158), toda ocene vodenja v SV, ki kažejo na to, kako pripadniki dojemajo uresničevanje zapisanih vrednot in sedanja pravila, so milo rečeno skrb zbujajoče in zanesljivo neprimerne za 4GW (str. 179) (Jakič, 2010). 
podlago za njeno spremembo, da se bo ta resnično zgodila, pa bo treba vsaj desetletje in vodje, ki bodo organizacijo ves čas načrtno vodili po poti sprememb, saj se mora kultura spremeniti na vseh treh ravneh, od katerih so prepričanja in temeljne predpostavke tiste, ki delujejo na nezavedni ravni in jih je izjemno težko spreminjati. Več o potrebnih spremembah organizacijske kulture SV bomo razpravljali $\mathrm{V}$ prihodnjem članku.

\subsection{Izobraževanje in usposabljanje $\mathbf{v}$ sistemu nacionalne varnosti}

Znotraj razprave o šolskem sistemu se moramo dogovoriti o tem, kdo bo v RS odgovoren za domoljubno oziroma državljansko vzgojo in kakšni so njeni cilji. O tem, da je nujna, ne more biti dvoma, nacionalna država ni samoumevna in če tega ne prenesemo na državljane, tvegamo, da država v očeh državljanov postane le davkoplačevalsko breme, kar lahko resno načne njeno legitimnost. Znotraj MO in SV se moramo odločiti, kako bomo postavili sistem profesionalnega vojaškega izobraževanja in usposabljanja, ki bo primeren vojnam prihodnosti. Na podlagi raziskave M. Jakič in osebnih opažanj trdimo, da sedanji ni primeren in komaj zadostuje trenutnim mirnodobnim potrebam ${ }^{35}$. Ob tem so odločitve o vključenosti $\mathrm{v}$ sistem javnega šolstva in o javnih kvalifikacijah učiteljev zadnje, o čemer bi bilo smiselno razpravljati. Glavno vprašanje je, kako postaviti profesionalni izobraževalni sistem za soočanje s četrto generacijo vojskovanja. Ko imamo odgovor na to vprašanje, si lahko šele zastavimo vprašanje, ali to lahko dobimo v povezavi s sistemom javnega šolstva in kako. Vojaško izobraževanje in usposabljanje morata predvsem oblikovati vodje, ki bodo sposobni sprejemati pravilne odločitve v kompleksnih situacijah, ki bodo prilagodljivi, samodisciplinirani in sposobni pravilne moralne presoje situacije, od taktične do strateške ravni. Tudi o tem bomo na ravni SV podrobneje razpravljali v prihodnjem članku.

\subsection{Popolnjevanje}

Vojaška učinkovitost po Renzovi ni vedno edini dejavnik, po katerem se države odločajo o sistemu popolnjevanja svojih oboroženih sil (Renz, 2014, str. 73). Finančna vzdržljivost in domače politične kalkulacije pogosto močno vplivajo na izbiro sistema popolnjevanja. Tako lahko tudi na primeru Slovenije ugotovimo, da se je za prehod na poklicno popolnjevanje leta 2004 skušala javnost prepričati tudi $\mathrm{z}$ argumenti, da bodo oborožene sile tako cenejše (gledano v odstotkih BDP med letoma 2004 in 2014 se je to tudi zgodilo), čeprav struktura obrambnih izdatkov ni nikoli dosegala želene. Predvsem pa je prehodu na poklicno popolnjevanje botrovala politična kalkulacija nepopularnosti služenja vojaškega roka med državljani ${ }^{36}$, ki je izhajala iz splošnega negativnega statusa vojske v družbi. ${ }^{37}$ Negativni status

\footnotetext{
${ }_{35}$ Žal SV, po avtorjevem vedenju, v vseh letih svojega obstoja ni opravila znanstvene raziskave, ki bi potrdila ali ovrgla primernost sistema izobraževanja in usposabljanja, predvsem častniškega kadra. Pa bi jo morala.

${ }^{36}$ Enako trdi tudi Primož Šavc, nekdanji direktor DOP MO, v intervjuju za revijo SV (Pišlar, 2016, str. 12).

${ }^{37}$ Uradno se sicer SV pogosto pohvali z zaupanjem državljanov vanjo, saj je med državnimi institucijami, ki jim državljani najbolj zaupajo, navadno na drugem mestu (za gasilci, ki so daleč pred vsemi), v resnici pa ji zaupanje izkazuje nekaj manj kot polovica državljanov, kar je prej vznemirljiv podatek kot ne.
} 
vojske $\mathrm{v}$ družbi tudi $\mathrm{v}$ sistemu poklicnega popolnjevanja negativno vpliva na pridobivanje kadra, zato SV tako vse od prehoda na poklicno popolnjevanje ne dosega načrtovanih novih zaposlitev, predvsem vojakov. Podobno izkušnjo s poklicnim popolnjevanjem so imeli v Ruski federaciji, kjer so kmalu ugotovili, da 1) za izključno poklicno popolnjene zmogljivosti oboroženih sil ni dovolj zanimanja in 2) da vse skupaj preveč stane (Barabanov, 2011). Zato so ambicije popolnoma poklicnega popolnjevanja enot kmalu opustili. Pri nas še po trinajstih letih vztrajamo pri sistemu, ki ne prinaša želenih rezultatov.

Res je, da je težnja po koncu hladne vojne v Evropi kazala k poklicnemu sistemu popolnjevanja, vendar nekatere najrazvitejše države kljub temu vzdržujejo kombinacijo poklicnega in naborniškega popolnjevanja, med njimi Finska, Norveška, Danska in Izrael. Tudi v ZDA, kjer so že dolgo tega opustili naborništvo, je general McChrystal leta 2012 govoril o tem, da bi morali uvesti naborništvo, da bi breme vojaške službe v družbi bolj enakomerno porazdelili (Renz, 2014, str. 73). Menimo, da je tudi za RS poklicno popolnjevanje oboroženih sil, kombinirano z eno izmed oblik naborništva ${ }^{38}$, ki zagotavlja dovolj veliko in usposobljeno rezervo, edina realna možnost za spoprijemanje z varnostnimi izzivi prihodnosti in za uspeh v četrti generaciji vojskovanja.

Sklep Za pristop k prenovi nacionalnovarnostnega sistema, predvsem pa Slovenske vojske v njem, ne more biti nobena stvar sveta. Kot ugotavlja Vandergriff, je vse, kar se izkaže za irelevantno v sodobnem in prihodnjem operativnem okolju, treba odpraviti (Vandergriff, 2006, str. 75). Razmislek o tem, kaj je relevantno in kaj ne, bo zahteval izjemen miselni napor, ki se mora začeti in končati znotraj strokovne javnosti, vmes pa je treba vanj vključiti tako politiko kot širšo družbo.

Predvsem je treba zagotoviti hitrejšo odzivnost ter boljšo usklajenost vseh elementov nacionalnovarnostnega sistema. Četrta generacija vojskovanja v RS ne more biti le stvar stalne sestave SV, kot tudi notranja varnost ne more biti več le stvar policije in zaščita ter reševanje samo stvar CZ. Varnost ni le stvar MO in MNZ, temveč tudi MZZ ter ministrstev za infrastrukturo, gospodarski razvoj in tehnologijo, izobraževanje, znanost in šport ter drugih, ne nazadnje družbe kot celote. Ključni zmogljivosti $\mathrm{v}$ tem novem nacionalnovarnostnem sistemu morata biti centralizirano sprejemanje strateških odločitev in moderniziran sistem vodenja in poveljevanja ter kontrole. ${ }^{39}$ Odzivnost je ključna. Razprave se morajo opraviti in končati že precej pred nastopom konflikta, kar seveda zahteva angažirano ukvarjanje politike $\mathrm{s}$ prihodnostjo. Morda bi bilo ob tem treba razmišljati tudi o spremenjeni vlogi in nalogi predsednika republike. Predsednik republike ima največjo mogočo legitimnost, saj

\footnotetext{
${ }^{38}$ Ali je to splošna vojaška obveznost vseh, vojaška obveznost samo moškega dela prebivalstva, selektivna vojaška obveznost (ko se iz bazena obveznikov izžreba potrebno število) ali kaj drugega, je stvar analize, demografskih dejavnikov in politične odločitve.

${ }^{39}$ Tako kot je nujno centralizirano sprejemanje odločitev na strateški ravni, je nujna tudinjihova decentralizirana izvedba, za katero pa je nujen sistem vodenja, poveljevanja in kontrole, ki bo to omogočal.
} 
je voljen neposredno, kar mu nalaga odgovornost, pravico in dolžnost, da skrbi za varnost državljanov.

Nujna je tudi popolna intelektualna prenova SV. To pomeni oblikovanje intelektualnega jedra znotraj SV, ki bo pristojno in odgovorno za pripravo potrebnih sprememb, imeti pa bo moralo tudi pristojnost in politično podporo za njihovo uveljavitev.

V naslednjem prispevku bomo podrobneje pogledali, kakšne oborožene sile potrebujemo za delovanje v četrti generaciji vojskovanja.

\section{Literatura}

1. Barabanov, M., 2011. Russia's New Army. Centre for Analysis of Strategies and Technologies, Moscow, Russia.

2. Državni zbor RS, 2013. Ustava Republike Slovenije. Ljubljana, Uradni list RS, št. 47/2013, z dne 31. 5. 2013: NPB9. https://zakonodaja.com/ustava/urs (16. 4. 2016).

3. Grizold, A.,1999. Obrambni sistem Republike Slovenije. MNZ, Visoka policijskovarnostna šola, Ljubljana.

4. Jakič, M., 2010. Organizacijska kultura in socialne reprezentacije v Slovenski vojski. FDV, Ljubljana.

5. Johnson, D., 2015. Russia's approach to Conflict-Implications for NATO's deterrence and defence. Researche paper No.111. Research division - NATO Defence College, Rome.

6. Lind, W.S., in Thiele, G.A., 2015. 4TH Generation Warfare Handbook. Castilia House. Kouvola, Finland (Kindle book).

7. Masten, A., 2016. Najbolj skrb vzbujajoče je, da iz naše vojske odhajajo tudi najbolj izurjeni. MMC-jev intervju z obramboslovcem. http://www.rtvslo.si/slovenija/najbolj-skrbvzbujajoce-je-da-iz-nase-vojske-odhajajo-tudi-najbolj-izurjeni/383705 (24. 4. 2016).

8. MO, 2016. Predlog Zakona o obrambi, poslan v medresorsko usklajevanje 13. 4. 2016. http://www.mo.gov.si/si/zakonodaja in dokumenti/predlogi predpisov/ (16. 4. 2016).

9. NATO, 2016. Bi-Sc Agreed Capability Codes and Capability Statements. Belgium: Supreme Allied Commander, Europe.

10. NATO, 2015. Framework for Future Alliance Operations. Supreme Allied Commander Transformation, Norfolk, Virginia.

11. Pišlar, M., 2016. Denarja za obrambne izdatke je premalo, če želimo SV obdržati: pogovor z generalnim direktorjem Direktorata za obrambno politiko Primožem Šavcem. Intervju v reviji SV št. 4, april 2016, MO, Ljubljana.

12. Renz, B., 2014. Russian Military Capabilities after 20 Years of Reform. Survival global politics and strategy, Volume 56 Number 3, IISS, Washington DC.

13. Resolucija o splošnem dolgoročnem programu razvoja in opremljanja Slovenske vojske do leta 2025 (ReSDPRO SV 2025). Državi zbor RS. Uradni list RS, št. 99/2010, z dne 7. 12. 2010.

14. Shlapak, D. A., in Johnson, M. W., 2016. Reinforcing deterrence on NATO's eastern flank; wargaming the defense of the Baltics. RAND Corporation, ARROYO CENTER.

15. Trampuš, J., 2011. Naše obrambne sile bi lahko prepolovili. Mladina 42. http://www. mladina.si/106478/nase-obrambne-sile-bi-lahko-prepolovili/(3. 2. 2016). http://www. rand.org/content/dam/rand/pubs/research_reports/RR1200/RR1253/RAND_RR1253.pdf (24. 4. 2016).

16. Vandergriff, D.E., 2006. Rasing the Bar; Creating and Nurturing Adaptability to Deal with the Changing Face of War. Center for Defence Information, Washington, D.C. 
17. Vlada RS, 2004. Zakon o obrambi (uradno prečiščeno besedilo). Ljubljana: Uradni list $R S$.

18. SIPRI Military Expenditure Database http://www.sipri.org/research/armaments/milex/ milex_database (3. 2. 2016). 